\title{
Suppression of Aurora-A oncogenic potential by c-Myc downregulation
}

\author{
Shangbin Yang ${ }^{1,2 *}$, Shun $\mathrm{He}^{1 *}$, Xiaobo Zhou ${ }^{1,3 *}$, \\ Mei Liu ${ }^{1}$, Hongxia Zhu ${ }^{1}$, Yihua Wang ${ }^{1}$, \\ Wei Zhang', Shuang Yan', Lanping Quan', \\ Jingfeng Bai ${ }^{1}$ and Ningzhi $\mathrm{Xu}^{1,4}$
}

\author{
${ }^{1}$ State Key Laboratory of Molecular Oncology and \\ Laboratory of Cell and Molecular Biology \\ Cancer Institute and Cancer Hospital \\ Chinese Academy of Medical Sciences and \\ Peking Union Medical College \\ Beijing, China \\ ${ }^{2}$ Current address: Department of Pathology \\ Ohio State University \\ 1645 Neil Ave, Columbus OH. 43210-1218 \\ ${ }^{3}$ Current address: Department of Pathology \\ Harvard Medical School \\ Boston, USA \\ ${ }^{4}$ Corresponding author: Tel, 86-10-67738220; \\ Fax, 86-10-67738220; E-mail, xningzhi@ public.bta.net.cn \\ *These authors contributed equally to this work. \\ DOI 10.3858/emm.2010.42.11.077
}

Accepted 29 September 2010

Available Online 1 October 2010

Abbreviations: CDDP, cisplatin; Dox, doxycycline; RNAi, RNA interference; TF, transcription factor

\begin{abstract}
The abnormality of serine/threonine kinase Aurora-A is seen in many types of cancers. Although in physiological context it has been shown to play a vital role in cellular mitosis, how this oncogene contributes to tumorigenesis remains unclear. Here we demonstrate that Aurora-A overexpression enhances both the expression level and transcriptional activity of c-Myc. The inhibition of c-Myc expression by RNA interference significantly impaired the oncogenic potential of Aurora-A, resulting in attenuated cellular proliferation and transformation rates as well as fewer centrosomal aberrations. Furthermore, downregulation of c-Myc effectively overcame Aurora-A-induced resistance to cisplatin in esophageal cancer cells. Taken together, our results suggest an important role for C-Myc in mediating the oncogenic activity of Aurora-A, which may in turn allow for future targeting of $\mathrm{C}-\mathrm{Myc}$ as a potential
\end{abstract} therapeutic strategy for tumors with Aurora-A over-
expression.

Keywords: aurora kinase; neoplasms; proto-oncogene proteins c-myc; RNA interference

\section{Introduction}

The evolutionarily conserved serine/threonine kinase Aurora-A is localized to the centrosome during the late $S$ phase and its expression peaks in the G2/M phase, during which time it plays a vital role in the regulation of accurate chromosome segregation and efficient completion of cytokinesis (Dutertre et al., 2002; Marumoto et al., 2002). The human Aurora-A gene is mapped to chromosome 20q13.2, a region commonly amplified in many epithelial cancers (Schlegel et al., 1995; Reznikoff et al., 1996; Forozan et al., 2000; Jazaeri et al., 2003). Overexpression of Aurora-A has been reported in a number of human tumors, including gastric and bladder cancers, gliomas, esophageal squamous cell cancers and hepatocellular cancers (Sen et al., 2002; Li et al., 2003; Jeng et al., 2004; Kamada et al., 2004; Klein et al., 2004; Tanaka et al., 2005). It was demonstrated that ectopic expression of Aurora-A in NIH 3T3 and Rat-1 fibroblast cells resulted in centrosome amplification. Both the wild type and constitutively active mutant Aurora-A plasmids were shown to be able to transform cells by forming tumors in mice xenografts (Bischoff et al., 1998; Zhou et al., 1998; Ewart-Toland et al., 2003). It has also been shown that overexpression of Aurora-A lead to an increased incidence of breast cancer in transgenic mice (Wang et al., 2006), further suggesting a carcinogenic role for Aurora-A.

Recent studies have demonstrated that Aurora-A amplification and/or overexpression were often accompanied by overexpression of another crucial oncogene, c-Myc. Genome-wide array comparative genomic hybridization $(\mathrm{aCGH})$ and $\mathrm{cDNA}$ microarray experiments showed that both Aurora- $A$ and $c-M y c$ genes were amplified in colorectal carcinomas and medulloblastomas (Neben et al., 2004; Lassmann et al., 2007). These two oncogenes were also shown to be co-overexpressed in mucinous cystic neoplasms of the pancreas and tamoxifen-treated breast cancer cells (Hodges et 
A

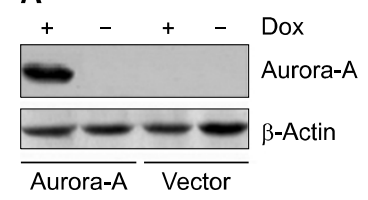

B

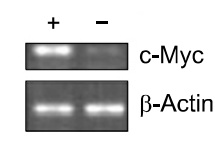

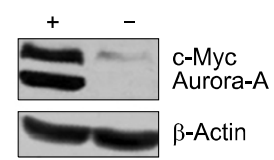

C

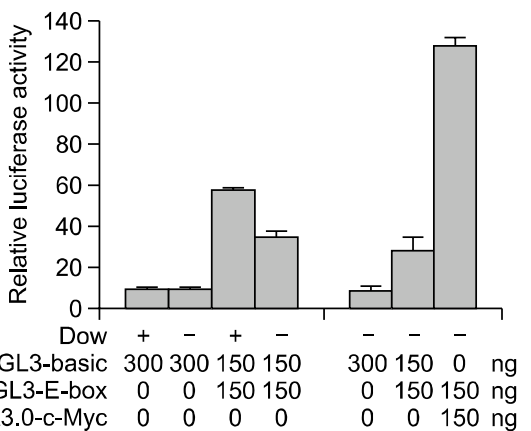

Figure 1. Aurora-A overexpression elevated c-Myc expression and transcriptional activity. (A) The establishment of Aurora-A-inducible cell line. Cell lysates from 293TR-Aur-myc or 293-TR-Vec treated with or without Dox $(2 \mu \mathrm{g} / \mathrm{ml})$ for $24 \mathrm{~h}$ were subjected to Western blotting with anti-myc antibodies. (B) The mRNA and protein level of c-Myc upon Aurora-A induction. 293-TR-Aur-myc cells were treated with or without Dox for $24 \mathrm{~h}$ and then harvested for RT-PCR and Western blotting. $\beta$-actin was used as a loading control. (C) The transcriptional activity of c-Myc upon Aurora-A induction. The 293-TR-Aur-myc cells were transfected with the indicated plasmids and luciferase activity was measured $48 \mathrm{~h}$ after transfection. The pcDNA3.0-c-Myc was used as a positive control for the constructed E-box reporter system. Transfection efficiency was normalized by co-transfection of pRL-TK. All experiments were performed three times.

al., 2003; Fukushima et al., 2004). Such data, when considered collectively, suggest a causative link between Aurora-A and c-Myc in tumorigenesis.

To better understand the possible interplay between Aurora-A and c-Myc in tumorigenesis, a doxycycline (Dox)-inducible expression system of Aurora-A was established. Using this system, we were able to demonstrate increased expression levels and transcriptional activity of c-Myc secondary to induced overexpression of Aurora-A. Inhibition of c-Myc expression via RNA interference (RNAi) impaired the ability of Aurora-A to promote cellular proliferation and colony formation in soft agar, as well as decreased the incidence of centrosomal abnormalities. Furthermore, depletion of c-Myc inhibited the Aurora-A-mediated chemoresistance to cisplatin in esophageal cancer cells. Based on these results, we propose that c-Myc plays a pivotal role in mediating Aurora-A-associated tumorigenesis and that c-Myc may serve as potential therapeutic target for cancers with abnormal Aurora-A expression.

\section{Results \\ Overexpression of Aurora-A elevates c-Myc expression and transcription activity}

To better understand the function of Aurora-A, we constructed an inducible, tetracycline-regulated expression system of Aurora-A. The parent T-REx ${ }^{\text {TM }}$ 293 cells (293-TR), which stably express the tetracycline repressor protein, were transfected with pcDNA4-Aurora-A-myc and selected for using Zeocin. After $24 \mathrm{~h}$ of induction with doxycycline (Dox), the myc-tagged Aurora-A was detected in 293TR-Aur-myc cells but hardly seen in control cells transfected with vector plasmid (Figure 1A), thus demonstrating the establishment of an inducible system efficiently expressing myc-tagged Aurora-A upon Dox treatment.

The c-Myc oncoprotein is an important regulator of many cellular processes, including cell growth and apoptosis (Dang, 1999). Recent studies have revealed a link between the overexpression of Aurora-A and c-Myc in several types of tumors. To examine the relationship between Aurora-A and c-Myc, we used our inducible system to detect c-Myc expression. Semi-quantitative RT-PCR and 
A

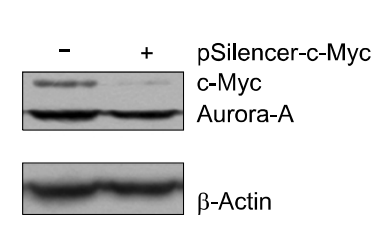

B $\rightarrow$ pSilencer-ct//Dox므 pSilencer-ct//Dox+ $\Delta-$ pSilencer-c-Myc/Dox-

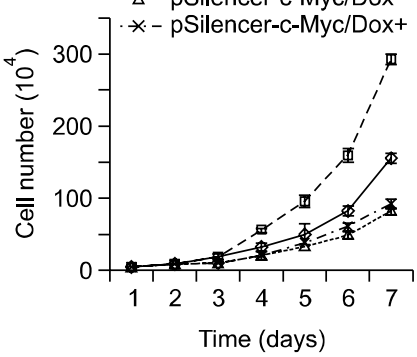

C

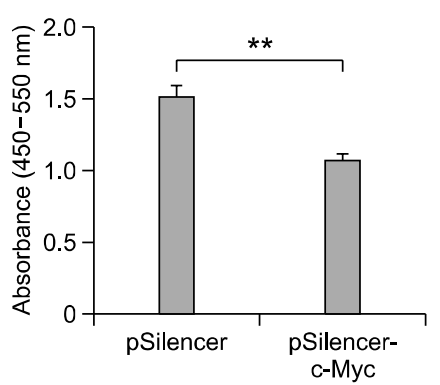

Figure 2. $c-M y c$ RNAi attenuated the increased cellular proliferation rate conferred by Aurora-A overexpression. (A) The efficiency of c-Myc RNAi plasmid. The 293-TRAur-myc cells were transfected with pSilencer-c-Myc or control plasmid for $48 \mathrm{~h}$ and then treated with Dox for $24 \mathrm{~h}$. Cells lysates were subjected to Western blotting for detection of c-Myc expression. (B) Cell growth curves. The 293-TR-Aur-myc cells $(5 \times$ $10^{4}$ ) were transfected with pSilencer-c-Myc or control plasmid and then treated with or without Dox. Cell numbers were counted every $24 \mathrm{~h}$. The data are shown as mean \pm SD for three independent cultures. (C) The proliferation rates were measured using a BrdU assay. The 293-TR-Aur-myc cells were treated with Dox after transfection with pSilencer-c-Myc or control plasmid. Then BrdU incorporation was performed to measure the proliferation rates, ${ }^{\star *} P<0.001$.

western blot analysis showed that upon Dox treatment, which induced overexpression of $\mathrm{Au}-$ rora-A, the expression of c-Myc was significantly enhanced on both the mRNA and protein level (Figure 1B). An E-box luciferase reporter plasmid containing six consensus c-Myc-binding sites was utilized to characterize the transcription activity of c-Myc. Similarly, we found that cells with Aurora-A overexpression showed an almost 2-fold increase in c-Myc transcription as compared to cells without induction of the reporter system (Figure 1C). Effects from variable factors were considered noncontributory, as Dox treatment did not significantly increase the luciferase activity of pGL3-basic reporter. Taken together, these data suggest a role for Aurora-A in the regulation of c-Myc.

\section{Inhibition of c-Myc expression retards Aurora-A-induced cell proliferation}

To further elucidate the role of c-Myc in Aurora-A-driven tumorigenesis, RNA interference (RNAi) was utilized to inhibit c-Myc expression, which was decreased after transfection with pSilencer-c-Myc, even in the presence of Aurora-A overexpression (Figure 2A). To investigate the effect of c-Myc downregulation on cellular proliferation, 293-TRAur-myc cells were treated with pSilencer-c-Myc in the presence and absence of Dox, and subsequent cell growth curves were then constructed after cell counting. Cells overexpressing Aurora-A showed a higher proliferation rate compared to the Doxuntreated cells. These data are consistent with previous findings demonstrating growth advantages conferred to NIH $3 \mathrm{~T} 3$ and Rat-1 cells by Aurora-A (Bischoff et al., 1998; Zhou et al., 1998; Ewart-Toland et al., 2003). C-Myc repression via RNAi resulted in attenuated cell growth for both Dox-treated and untreated cells. However, the proliferation rate of Dox-treated cells decreased more abruptly and dropped to almost the same level of Dox-untreated cells, indicating that inhibition of c-Myc expression efficiently counteracts the growth advantage conferred by Aurora-A (Figure 2B). The ability of c-Myc RNAi to suppress proliferation of Aurora-A overexpression cells was 
further confirmed by BrdU assay $(P<0.001$, Figure 2C).

\section{Inhibition of c-Myc expression reduces Aurora-A-induced anchorage-independent growth potential of cells}

It has been previously demonstrated that transfection of Aurora-A transforms Rat1 cells in soft agar assays (Bischoff et al., 1998). This was further confirmed in our inducible system (Figure $3 \mathrm{~A}$, upper panel). To verify the role of c-Myc in the transformation, soft agar experiments were simultaneously conducted using 293-TR-Aur-myc cells either with or without c-Myc suppression. As shown in Figure $3 \mathrm{~A}$, in the absence of c-Myc repression, the 293-TR-Aur-myc cells formed significantly more and larger colonies in soft agar after Dox induction. In contrast, the cells pretreated with c-Myc RNAi formed much fewer and smaller colonies (nearly a third of the control cell). More importantly, the colony formation rates showed little, if any, change when the cells were subjected to Dox treatment (Figure 3B), demonstrating the efficiency of c-Myc suppression on blocking the anchorage-independent growth potential granted by Aurora-A overexpression.

\section{Inhibition of c-Myc expression alleviates Aurora-A-induced centrosomal abnormalities}

Zhou et al. (1998) first reported that overexpression of Aurora-A in NIH 3T3 cells induced centrosome amplification. We observed similar phenotypes in our constructed 293-TR- Aur-myc cells after $24 \mathrm{~h}$ of Dox treatment, which resulted in cells possessing more than two centrosomes (Figure 4A). As time went by, the quantity of cells showing centrosome amplification increased steadily and reached up to $11 \%$ after 20 days' induction. However, prolonged Dox exposure eventually resulted in a decrease, rather than continued increase, of this number (Figure 4B). The centrosome amplification was believed to be caused by Aurora-A specifically, as abnormal centrosomes were extremely rare in control 293TR-Vec cells. These data verify the role of Aurora-A in inducing centrosome amplification. To determine c-Myc's role in this process, we transfected 293-TR-Aur-myc cells with pSilencer-c-Myc for three days and then induced with Dox for one day. As shown in Figure 4C, nearly $5 \%$ of cells were shown to have centrosome amplification when treated with Dox. However, the percentage of cells harboring centrosome abnormalities dropped to less than $1 \%$ when subjected to c-Myc depletion
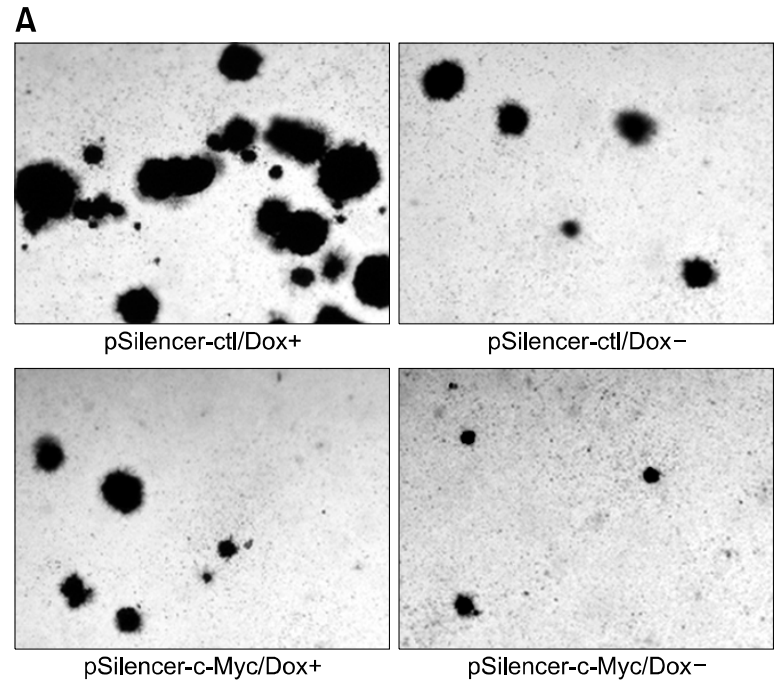

B

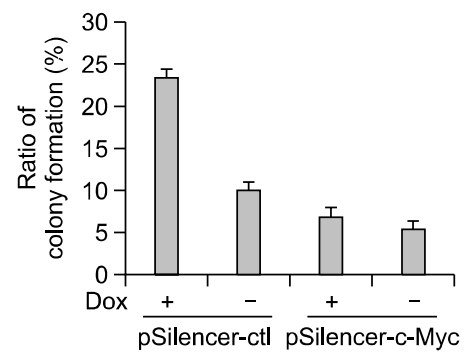

Figure 3. c-Myc RNAi impaired colony formation rate caused by $A u-$ rora-A overexpression. (A) The colonies formed in soft agar. The 293TR-Aur-myc cells were transfected with pSilencer-c-Myc or control plasmid for $48 \mathrm{~h}$ and then treated with or without Dox. Five hundred cells were replated into soft agar and incubated for two weeks. The colonies were visualized by staining with $0.2 \%$ piodonitrotetrazolium violet. (B) The colony formation rates were calculated by counting the average number of colonies in different treatment groups. All experiments were performed at least three times with consistent and reproducible results.

(Figure 4C), thus indicating the abrogation of the oncogenic effects of overexpressed Aurora-A.

\section{Inhibition of c-Myc expression overcomes Aurora-A-mediated resistance to cisplatin}

It has been shown that that Aurora-A overexpression renders cancer cells resistant to some chemotherapeutic drugs, including taxol, cisplatin and etoposide (Bischoff et al., 1998; Ewart-Toland et al., 2003). As demonstrated above, C-Myc RNAi inhibit a series of neoplastic phenotypes induced by Aurora-A in our 293 inducible cells. This lead us to speculate that downregulation of c-Myc may also override Aurora-A-mediated chemoresistance in cancer cells. To test this hypothesis, an esophageal cancer cell line (EC9706), which stably expresses high levels of Aurora-A, was generated 
A

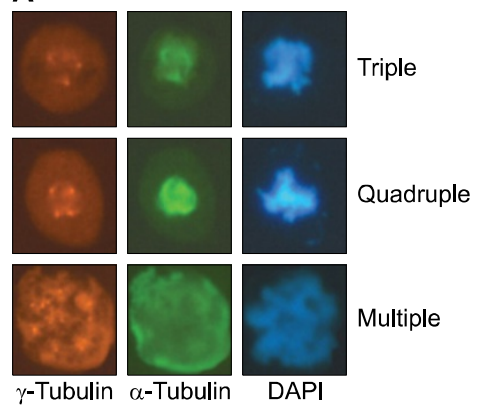

B

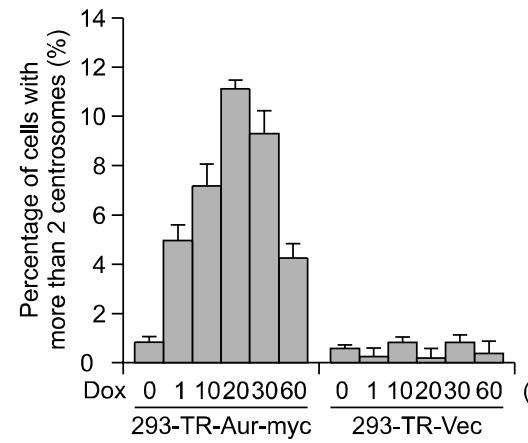

C

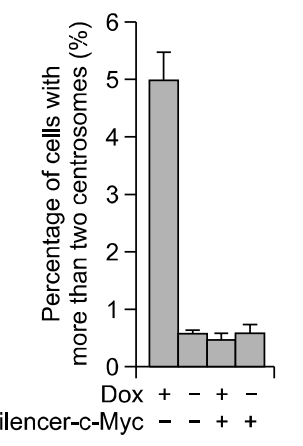

Figure 4. c-Myc RNAi alleviated centrosome abnormalities induced by Aurora-A overexpression. (A) The abnormal centrosomes induced by Aurora-A. The 293TR-Aur-myc cells were incubated with Dox for $48 \mathrm{~h}$ and then triple-stained with DAPI (blue), anti- $\alpha$-tubulin (green) and anti- $\gamma$-tubulin (red) to show the excessive numbers of centrosomes. (B) The percentage of cells with centrosome abnormalities. The 293TR-Aur-myc and 293-TR-Vec cells were treated with Dox for the indicated time intervals. The cells with abnormal centrosomes were counted (at least 200 cells were counted). (C) The percentage of cells with centrosome abnormalities in 293-TRAur-myc cells with prior transfection of pSilencer-c-Myc or control plasmid. At least 200 cells were counted.

by transfection with pcDNA4-Aurora-A. Cell viability was assessed in the presence and absence of c-Myc RNAi when cells were exposed to cisplatin (CDDP) for $36 \mathrm{~h}$. As presented in Figure 5, CDDP treatment decreased the viability by $60 \%$ in EC9706-pcDNA4 cells, while ectopic expression of Aurora-A in EC9706-Aur cells conferred cellular protection, as evidenced by a decreased viability of only $30 \%$. EC9706-pcDNA4 cells that were either pretreated with pSilencer-control or with pSilencer-c-Myc showed a similar decrease upon CDDP exposure. Interestingly, although pretreatment with pSilencer-c-Myc showed little effect on EC9706pcDNA4 cells, downregulation of c-Myc significantly restored the sensitivity of EC9706-Aur cells to CDDP, decreasing the viability by nearly $60 \%$, which was almost the same level of EC9706pcDNA4 cells, suggesting an almost complete reversal of the resistance conferred by Aurora-A.

\section{Discussion}

There is increasingly heightened interest in the mechanism by which Aurora-A transforms cell. Recently, Katayama et al. (2004) reported that overexpression of Aurora-A induced Mdm2-mediated destabilization of p53 through phosphorylation of p53 at Ser315. Along similar lines, Liu and colleagues discovered that Aurora-A inhibited DNA binding and transcriptional activity of p53 by phosphorylation of p53 at Ser215 (Liu et al., 2004), resulting in downregulation of check-point response and an increased rate of cell transformation. Yang et al. (2006) discovered that Aurora-A induced cell survival and chemoresistance through activation of Akt in ovarian cancer cells. These findings thus begins to elucidate the means by which Aurora-A plays an oncogenic role. In our present study, c-Myc expression at both the mRNA and the protein level, and consequently its transcriptional activity, were shown to be up- 


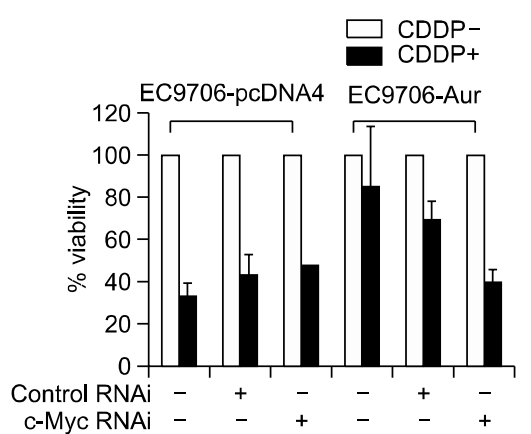

Figure 5. c-Myc RNAi overcame Aurora-A-mediated resistance to cisplatin. The EC9706-Aur and EC9706-pcDNA4 esophogeal cancer cell lines were transfected with pSilencer-c-Myc or control plasmid using LipofectAMINE ${ }^{\mathrm{TM}} 2000$ and then exposed to CDDP at a concentration of $10 \mu \mathrm{M}$ for $55 \mathrm{~h}$. Cell viability was determined using an MTT assay.

regulated upon Aurora-A overexpression. To further explore the role of $\mathrm{c}-\mathrm{Myc}$ in mediating the oncogenic potential of Aurora-A, RNAi inhibition of c-Myc was utilized. Our results showed that repression of c-Myc could effectively counteract the oncogenic effects of Aurora-A, leading to attenuated in vitro cell proliferation, impaired colony formation in soft agar and fewer centrosomal abnormalities. Furthermore, downregulation of c-Myc was also found to override resistance to CDDP in esophageal cancer cells. Our data strongly suggest an essential role for c-Myc in mediating Aurora-A's oncogenic potential. In accordance with our results, a research group recently demonstrated that Aurora-A contributes to human neurablastomas by mediating stabilization of another Myc family protein N-Myc (Otto et al., 2009). These observation together suggest the complex relationship between Aurora-A and Myc family in tumorigenesis.

It is known that overexpression of Aurora-A leads to centrosome abnormalities. Our corroborating data show that the ratio of cells harboring excess centrosomes increased along with Aurora-A induction time, while the aberrant centrosomes were hardly detected in the cells with prior treatment of c-Myc RNAi. These results suggest that the abnormal increase of centrosomes induced by Aurora-A is at least partially dependent on c-Myc expression. Indeed, N-Myc, a close relative of $\mathrm{c}-\mathrm{Myc}$, has recently been shown to induce centrosome amplification in neurablastoma cells (Slack et al., 2007), suggesting the potential regulation of Myc proteins over centrosome number. Yet the molecular mechanism by which c-Myc is involved in this context remains elusive. According to our results, Aurora-A overexpression prompts c-Myc transcription and upregulates a number of its target genes. Considering the oncogenic properties of c-Myc, it may therefore be possible that certain downstream effectors of cMyc are involved in overriding the mitotic spindle checkpoint and thereby enable inappropriate anaphase onset, which is followed by a failure to undergo cytokinesis and the subsequent generation of abnormal centrosomes (Meraldi et al., 2002). It's worthy of note that the mechanism by which Aurora-A enhances c-Myc expression is still unclear. Recently Dar and colleagues discovered that Aurora-A increased the phosphorylation of GSK3 $\beta$ at Ser9, resulting in activation of $\beta$-catenin/TCF4 pathway (Dar et al., 2009). As $\beta$ catenin/TCF4 pathway is a putative upstream regulator of c-Myc, it provides a tempting scenario for the induction of c-Myc by Aurora-A, yet further work is needed to testify this relationship.

Elevated expression of Aurora-A is reportedly associated with some parameters of clinical oncologic aggressiveness, such as high histological grade, invasion and increased rates of metastasis in several types of cancers (Sen et al., 2002; Jeng et al., 2004). Because tumor cells overexpressing Aurora-A show resistance to Taxol or nocodazole by disrupting the checkpoint that is targeted by these chemotherapeutic agents, it is likely that an alternative treatment strategy is required for these specific cancers (Anand et al., 2003, Jiang et al., 2003). Recently, three novel small-molecule inhibitors of Aurora-A, termed Hesperadin, ZM4474739 and VX-680, have been described (Ditchfield et al., 2003; Hauf et al., 2003; Harrington et al., 2004). However, considering the physiological function of Aurora-A, direct blockade of this protein may potentially induce oncogenic side effects by generating chromosomal instability. Our work has shown that c-Myc plays an important role in mediating Aurora-A's oncogenic activity, and prior studies have explored this in terms of therapeutic strategy targeting. Jain and colleagues demonstrated that transient inactivation of c-Myc induced a sustained loss of neoplastic phenotypes of osteogenic sarcoma cells (Jain et al., 2002). In our own previous studies, downregulation of c-Myc by RNAi effectively inhibited MCF-7 breast tumor cells growth in vitro and in vivo (Wang et al., 2005). Together, these data suggest that C-Myc may be a promising target for human cancer treatment. In our current work, c-Myc silencing via RNAi significantly inhibits a series of neoplastic phenotypes normally induced by Aurora-A. Thus, the inhibition of oncogenes acting downstream of Aurora-A, such as C-Myc, may offer alternative means to treat the cancers with abnormal Aurora-A expression. 


\section{Methods}

\section{Plasmid constructs, cell culture and transfection}

Full-length Aurora- $A$ coding sequence was cloned into BamHI/Xhol sites of the pcDNA4 ${ }^{\mathrm{TM}} / \mathrm{TO} / \mathrm{myc}$-His-B (Invitrogen) vector (abbreviated to pcDNA4-Aurora-A-myc). The primers were as follows: 5'-CGGGATCCATGGACCGATCTAAAGAAAAC-3' (upper) and 5'-GCCTCGAGTAAGACTGTTTGCTAGC-3' (lower). Six tandem copies of the E-box consensus sequences fused to a TATA-like promoter $\left(\mathrm{P}_{\mathrm{TAL}}\right)$ were subcloned from pMyc-SEAP (Clontech) into $\mathrm{Kpnl} /$ Hindlll sites of the pGL3-basic vector (Invitrogen), abbreviated as pGL3-E-box. Full-length $c-M y c$ gene was cloned into BamHI/EcoRI sites of pcDNA3.0 with the primers 5'-CGGGATCCACGATGCCCCTACACGTTAGC-3' and 5'-CGGAATTCTTACGCACAAGAGTTCCGTAG-3', abbreviated as pcDNA3.0-c-Myc. The plasmids pSilencerc-Myc and pSilencer-ctl were constructed as previously described (Wang et al., 2005). The parental T-REx ${ }^{\mathrm{TM}}-293$ cells (Invitrogen, abbreviated to 293-TR) were grown in DMEM (Invitrogen) and EC9706 cells (kindly provided by Prof. M. Wang) were maintained in 1640 (Invitrogen). All media were supplemented with $10 \%$ fetal bovine serum (Gibco BRL). All transfection assays were conducted with LipofectAMINE $^{T M} 2000$ Reagent (Invitrogen) according to the manufacturer's instructions. For the establishment of the Aurora-A-inducible expression system, 293-TR cells were transfected with pcDNA4-Aurora-A-myc or pcDNA4 ${ }^{\mathrm{TM}}$, $\mathrm{TO} / \mathrm{myc}-\mathrm{His}-\mathrm{B}$, and selected with $100 \mu \mathrm{g} / \mathrm{ml}$ Zeocin (Invitrogen). The resistant mono-clone was verified by Western blotting, and designated as 293-TR-Aur-myc or 293TR-Vec.

\section{Cellular proliferation and soft agar assays}

293-TR-Aur-myc cells transfected with pSilencer-c-Myc or pSilencer-ctl were harvested and replated at a density of $500 \mathrm{cells} / \mathrm{mm}^{2}$ in triplicate and were treated with $2 \mu \mathrm{g} / \mathrm{ml}$ Dox or left as controls. The total cell numbers were determined daily using a hematocytometer and an Olympus inverted microscope. Cell viability was assessed by using trypan blue exclusion.

The Bromodeoxyuridine (BrdU) cell proliferation assay was done using the BrdU Cell Proliferation Assay Kit (Calbiochem) according to the manufacturer's protocol. In brief, cells were seeded into a 96-well culture dish at $1 \times$ $10^{5} \mathrm{cells} / \mathrm{ml}$ for $24 \mathrm{~h}$ and incubated with BrdU working solution for additional $12 \mathrm{~h}$. After supernatant was removed, the cells were fixed and denatured with the Fixative/Denaturing Solution for $30 \mathrm{~min}$ at room temperature (RT). Then $100 \mu \mathrm{l}$ of the anti-BrdU antibody solution was added and allowed to incubate for $1 \mathrm{~h}$ at RT. Unbound antibody was washed away and the secondary antibody solution was added and allowed to incubate for $30 \mathrm{~min}$. The amount of incorporated BrdU was determined using a spectrophotometric plate reader at dual wavelengths of 450-540 $\mathrm{nm}$ after the 15-min incubation with Substrate Solution in the dark. The assay was terminated with the addition of Stop Solution.

Soft agar assay was performed as previously described. Briefly, 2 days after transfection, 293-TR-Aur-myc cells (1000 cells per well) were mixed with tissue culture me- dium containing $0.6 \%$ agar to a final agar concentration of $0.3 \%$. Then $1 \mathrm{ml}$ samples of this cell suspension were immediately plated onto the bottom agar layer and allowed to solidify for 20-25 minutes at room temperature. After 2 weeks of incubation at $37^{\circ} \mathrm{C}$ with $5 \% \mathrm{CO}_{2}$, the top layer of the culture was stained with $0.2 \%$ piodonitrotetrazolium violet (Sigma).

\section{RNA extraction and RT-PCR}

Total RNA was extracted from cells with TRIZOL Reagent (Invitrogen) according to the manufacturer's protocol. Five micrograms of total RNA extracted from cells was used as a template for cDNA synthesis in $25 \mu$ of reaction mixture with $2.5 \mathrm{mM}$ oligo $\mathrm{d}(\mathrm{T})$ primers and M-MLV Reverse Transcriptase (Promega) at $37^{\circ} \mathrm{C}$ for 1 hour followed by $95^{\circ} \mathrm{C}$ for $10 \mathrm{~min}$. All PCR reactions were performed using standard PCR conditions: $95^{\circ} \mathrm{C} 5 \mathrm{~min}, 95^{\circ} \mathrm{C} 1 \mathrm{~min}$, annealing at $56^{\circ} \mathrm{C}$ for $1 \mathrm{~min}$, extension at $72^{\circ} \mathrm{C}$ for $1 \mathrm{~min}$ for 30 cycles, and a final extension at $72^{\circ} \mathrm{C}$ for $10 \mathrm{~min}$. The reaction products were visualized by electrophoresis at $70 \mathrm{~V}$ for 30 min in $2 \%$ agarose gel containing $0.5 \mathrm{ug} / \mathrm{ml}$ ethidium bromide and quantitated by densitometry using Gel-Pro Analyzer version 3.1 (Media Cybernetics).

\section{Western blotting analyses}

Cells were harvested at specified time points, total protein extracts were obtained using lysis buffer and Western blotting analysis was performed with the use of conventional protocols as previously described (Zhou et al., 2003). Briefly, equal amounts of total protein were separated on $12 \%$ acrylamide gels using standard sodium dodecyl sulfate-polyacrylamide gel electrophoresis (SDSPAGE) technique. After transfer to nitrocellulose membranes (OPTITRAN), proteins were detected with anti-myc antibodies (Myc 9E10; 1:1000; Santa Cruz), which were then followed by incubation with anti-mouse IgG-horseradish peroxide-conjugated secondary antibodies (Zhongshan Company) and then identified using a chemiluminescence luminal detection kit (Santa Cruz). The same membrane was also probed with anti- $\beta$-actin antibodies (AC-15; 1:5000; Sigma) as a control.

\section{Reporter assay}

Cells were replated and transfected in 24-well plates with either pGL3-E-box (150 ng) or pGL3-basic (150 ng) and the internal control plasmid pRL-TK (5 ng) using LipofectAMINE ${ }^{T M} 2000$ Reagent (Invitrogen). After transfection, cells were treated with or without $2 \mu \mathrm{g} / \mathrm{ml}$ Dox for 3 days. Then, luciferase activities were determined using the Dualluciferase reporter assay system (Promega). Firefly luciferase activity was normalized to Renilla luciferase activity. All results were expressed as means $\pm S D$ for three independent cultures.

\section{Immunofluorescence staining}

Immunofluorescence staining was performed as previously described (Yih et al., 2006) to detect the centrosome amplification. We grew cells on glass coverslips in 6-well 
plates and fixed them with $90 \%$ methanol at $-20^{\circ} \mathrm{C}$ for 10 min after appropriate induction or transfection. The cells were washed twice with ice-cold PBS and co-incubated for $1 \mathrm{~h}$ at $37^{\circ} \mathrm{C}$ with a rabbit anti- $\gamma$-tubulin antibody (AK15; 1:200; Sigma) and a mouse anti- $\alpha$-tubulin antibody (clone B512; 1:200; Sigma). Unbound antibodies were removed with a triple wash of PBS containing $0.2 \%$ Twen-20 (PBST) and then cells were incubated for $30 \mathrm{~min}$ at $37^{\circ} \mathrm{C}$ in the dark with FITC-coupled anti-mouse and TRITC-coupled anti-rabbit secondary antibodies (Zhongshan Company). The nuclei were simultaneously counterstained with 0.1 $\mu \mathrm{g} / \mathrm{ml} \mathrm{4,} \mathrm{6-diamino-2-phenylindole} \mathrm{(DAPI,} \mathrm{Sigma).} \mathrm{After}$ rinsing with PBST, cells were mounted with glycerol and examined under a fluorescence microscope (Olympus). Three independent experiments, each including at least 200 cells, were analyzed to calculate the percentage of cells with more than two centrosomes.

\section{Acknowledgements}

We thank Prof. Quan Chen for the parental T-REx ${ }^{T M}-293$ cells. This work was supported by Beijing Natural Science Foundation (5102038), National Natural Science Foundation (30721001, 39925020) and National Basic Research Program (2004CB518701), P. R. China.

\section{References}

Anand S, Penrhyn-Lowe S, Venkitaraman AR. AURORA-A amplification overrides the mitotic spindle assembly checkpoint, inducing resistance to Taxol. Cancer Cell 2003;3: 51-62

Bischoff JR, Anderson L, Zhu Y, Mossie K, Ng L, Souza B, Schryver B, Flanagan P, Clairvoyant F, Ginther C, Chan CS, Novotny M, Slamon DJ, Plowman GD. A homologue of Drosophila aurora kinase is oncogenic and amplified in human colorectal cancers. EMBO J 1998;17:3052-65

Dang CV. c-Myc target genes involved in cell growth, apoptosis, and metabolism. Mol Cell Biol 1999;19:1-11

Dar AA, Belkhiri A, El-Rifai W. The aurora kinase A regulates GSK-3beta in gastric cancer cells. Oncogene 2009;28: 866-75

Ditchfield C, Johnson VL, Tighe A, Ellston R, Haworth C, Johnson T, Mortlock A, Keen N, Taylor SS. Aurora B couples chromosome alignment with anaphase by targeting BubR1, Mad2, and Cenp-E to kinetochores. J Cell Biol 2003; 161:267-80

Dutertre S, Descamps S, Prigent C. On the role of aurora-A in centrosome function. Oncogene 2002;21:6175-83

Ewart-Toland A, Briassouli P, De Koning JP, Mao JH, Yuan $\mathrm{J}$, Chan F, Maccarthy-Morrogh L, Ponder BA, Nagase H, Burn J, Ball S, Almeida M, Linardopoulos S, Balmain A. Identification of Stk6/STK15 as a candidate low-penetrance tumor-susceptibility gene in mouse and human. Nat Genet 2003;34:403-12

Forozan F, Mahlamaki EH, Monni O, Chen Y, Veldman R, Jiang Y, Gooden GC, Ethier SP, Kallioniemi A, Kallioniemi
OP. Comparative genomic hybridization analysis of 38 breast cancer cell lines: a basis for interpreting complementary DNA microarray data. Cancer Res 2000;60:4519-25

Fukushima N, Sato N, Prasad N, Leach SD, Hruban RH, Goggins M. Characterization of gene expression in mucinous cystic neoplasms of the pancreas using oligonucleotide microarrays. Oncogene 2004;23:9042-51

Harrington EA, Bebbington D, Moore J, Rasmussen RK, Ajose-Adeogun AO, Nakayama T, Graham JA, Demur C, Hercend T, Diu-Hercend A, Su M, Golec JM, Miller KM. VX-680, a potent and selective small-molecule inhibitor of the Aurora kinases, suppresses tumor growth in vivo. Nat Med 2004;10:262-7

Hauf S, Cole RW, Laterra S, Zimmer C, Schnapp G, Walter R, Heckel A, Van Meel J, Rieder CL, Peters JM. The small molecule Hesperadin reveals a role for Aurora B in correcting kinetochore-microtubule attachment and in maintaining the spindle assembly checkpoint. J Cell Biol 2003;161:281-94

Hodges LC, Cook JD, Lobenhofer EK, Li L, Bennett L, Bushel PR, Aldaz CM, Afshari CA, Walker CL. Tamoxifen functions as a molecular agonist inducing cell cycle-associated genes in breast cancer cells. Mol Cancer Res 2003;1:300-11

Jain M, Arvanitis C, Chu K, Dewey W, Leonhardt E, Trinh M, Sundberg CD, Bishop JM, Felsher DW. Sustained loss of a neoplastic phenotype by brief inactivation of MYC. Science 2002;297:102-4

Jazaeri AA, Lu K, Schmandt R, Harris CP, Rao PH, Sotiriou C, Chandramouli GV, Gershenson DM, Liu ET. Molecular determinants of tumor differentiation in papillary serous ovarian carcinoma. Mol Carcinog 2003;36:53-9

Jeng YM, Peng SY, Lin CY, Hsu HC. Overexpression and amplification of Aurora-A in hepatocellular carcinoma. Clin Cancer Res 2004;10:2065-71

Jiang Y, Zhang Y, Lees E, Seghezzi W. AuroraA overexpression overrides the mitotic spindle checkpoint triggered by nocodazole, a microtubule destabilizer. Oncogene 2003;22:8293-301

Kamada K, Yamada Y, Hirao T, Fujimoto H, Takahama Y, Ueno M, Takayama T, Naito A, Hirao S, NAKAJIMA Y. Amplification/overexpression of Aurora-A in human gastric carcinoma: potential role in differentiated type gastric carcinogenesis. Oncol Rep 2004;12:593-9

Katayama H, Sasai K, Kawai H, Yuan ZM, Bondaruk J, Suzuki F, Fujii S, Arlinghaus RB, Czerniak BA, Sen S. Phosphorylation by aurora kinase $\mathrm{A}$ induces Mdm2-mediated destabilization and inhibition of p53. Nat Genet 2004;36: 55-62

Klein A, Reichardt W, Jung V, Zang KD, Meese E, Urbschat S. Overexpression and amplification of STK15 in human gliomas. Int J Oncol 2004;25:1789-94

Lassmann S, Weis R, Makowiec F, Roth J, Danciu M, Hopt $U$, Werner M. Array CGH identifies distinct DNA copy number profiles of oncogenes and tumor suppressor genes in chromosomal- and microsatellite-unstable sporadic colorectal carcinomas. J Mol Med 2007;85:293-304

Li D, Zhu J, Firozi PF, Abbruzzese JL, Evans DB, Cleary K, 
Friess H, Sen S. Overexpression of oncogenic STK15/ BTAK/Aurora A kinase in human pancreatic cancer. Clin Cancer Res 2003;9:991-7

Liu Q, Kaneko S, Yang L, Feldman RI, Nicosia SV, Chen J, Cheng JQ. Aurora-A abrogation of p53 DNA binding and transactivation activity by phosphorylation of serine 215 . J Biol Chem 2004;279:52175-82

Marumoto T, Hirota T, Morisaki T, Kunitoku N, Zhang D, Ichikawa Y, Sasayama T, Kuninaka S, Mimori T, Tamaki N, Kimura M, Okano Y, Saya H. Roles of aurora-A kinase in mitotic entry and $\mathrm{G} 2$ checkpoint in mammalian cells. Genes Cells 2002;7:1173-82

Meraldi P, Honda R, Nigg EA. Aurora-A overexpression reveals tetraploidization as a major route to centrosome amplification in p53-/- cells. EMBO J 2002;21:483-92

Neben K, Korshunov A, Benner A, Wrobel G, Hahn M, Kokocinski F, Golanov A, Joos S, Lichter P. Microarray-based screening for molecular markers in medulloblastoma revealed STK15 as independent predictor for survival. Cancer Res 2004;64:3103-11

Otto T, Horn S, Brockmann M, Eilers U, Schuttrumpf L, Popov $\mathrm{N}$, Kenney AM, Schulte JH, Beijersbergen R, Christiansen $\mathrm{H}$, Berwanger $\mathrm{B}$, Eilers $\mathrm{M}$. Stabilization of $\mathrm{N}-\mathrm{Myc}$ is a critical function of Aurora A in human neuroblastoma. Cancer Cell 2009;15:67-78

Reznikoff CA, Belair CD, Yeager TR, Savelieva E, Blelloch $\mathrm{RH}$, Puthenveettil JA, Cuthill S. A molecular genetic model of human bladder cancer pathogenesis. Semin Oncol 1996;23:571-84

Schlegel J, Stumm G, Scherthan H, Bocker T, Zirngibl H, Ruschoff J, Hofstadter F. Comparative genomic in situ hybridization of colon carcinomas with replication error. Cancer Res 1995;55:6002-5

Sen S, Zhou H, Zhang RD, Yoon DS, Vakar-Lopez F, Ito S, Jiang F, Johnston D, Grossman HB, Ruifrok AC, Katz RL,
Brinkley W, Czerniak B. Amplification/overexpression of a mitotic kinase gene in human bladder cancer. J Natl Cancer Inst 2002;94:1320-9

Slack AD, Chen Z, Ludwig AD, Hicks J, Shohet JM. MYCN-directed centrosome amplification requires MDM2mediated suppression of p53 activity in neuroblastoma cells. Cancer Res 2007;67:2448-55

Tanaka E, Hashimoto Y, Ito T, Okumura T, Kan T, Watanabe G, Imamura M, Inazawa J, Shimada Y. The clinical significance of Aurora-A/STK15/BTAK expression in human esophageal squamous cell carcinoma. Clin Cancer Res 2005; 11:1827-34

Wang X, Zhou YX, Qiao W, Tominaga Y, Ouchi M, Ouchi T, Deng CX. Overexpression of aurora kinase $A$ in mouse mammary epithelium induces genetic instability preceding mammary tumor formation. Oncogene 2006;25:7148-58

Wang YH, Liu S, Zhang G, Zhou CQ, Zhu HX, Zhou XB, Quan LP, Bai JF, Xu NZ. Knockdown of c-Myc expression by RNAi inhibits MCF-7 breast tumor cells growth in vitro and in vivo. Breast Cancer Res 2005;7:R220-8

Yang H, He L, Kruk P, Nicosia SV, Cheng JQ. Aurora-A induces cell survival and chemoresistance by activation of Akt through a p53-dependent manner in ovarian cancer cells. Int J Cancer 2006;119:2304-12

Yih LH, Tseng YY, Wu YC, Lee TC. Induction of centrosome amplification during arsenite-induced mitotic arrest in CGL-2 cells. Cancer Res 2006;66:2098-106

Zhou CQ, Liu S, Xue LY, Wang YH, Zhu HX, Lu N, Xu NZ. Down-regulation of gamma-synuclein in human esophageal squamous cell carcinoma. World J Gastroenterol 2003;9: 1900-3

Zhou H, Kuang J, Zhong L, Kuo WL, Gray JW, Sahin A, Brinkley BR, Sen S. Tumour amplified kinase STK15/BTAK induces centrosome amplification, aneuploidy and transformation. Nat Genet 1998;20:189-93 